\title{
Mobilising farmers to stop land degradation: a different discourse from Burundi
}

\author{
Aad Kessler ${ }^{1}$, Erik Slingerland ${ }^{2}$, Micael Beun ${ }^{2}$, Ruben Winne ${ }^{3}$, Laura Pol ${ }^{1}$, and Laurie \\ Reemst $^{1}$ \\ ${ }^{1} \mathrm{WUR}$ \\ ${ }^{2}$ IFDC \\ ${ }^{3}$ Oxfam Novib
}

May 5, 2020

\begin{abstract}
Stopping land degradation is one of the biggest challenges worldwide and particularly in Burundi, which currently faces unprecedented rates of soil loss and food insecurity. This paper proposes a different development discourse on how to stop land degradation, and presents results and lessons learned of a bottom-up inclusive approach implemented since 2014 in Burundi: the Integrated Farm Planning approach (PIP) approach. This approach aims to build a solid foundation for sustainable change towards enhanced food production and good land stewardship, based on three foundation principles (motivation, stewardship and resilience) and three guiding principles (empowerment, integration and collaboration). Findings from an impact study on the PIP approach and testimonies of farmers from a qualitative study show profound changes in land management practices and diversity of activities on the farm, as well as in the social cohesion in households and villages. Based on a vision and a plan, nearly 80,000 motivated households are currently actively involved to stop land degradation and make their farms more productive, while in all PIP villages concrete collective action is undertaken for sustainable land stewardship. Given that these actions are widespread and come along with a change in mind-set rooted in all three foundation principles, the paper concludes that the PIP approach is able to effectively build a foundation for sustainable change. Five key lessons from this experience reveal the key elements of a different development discourse that actually motivates and mobilises farmers to stop land degradation.
\end{abstract}

Mobilising farmers to stop land degradation:

a different discourse from Burundi

Aad Kessler ${ }^{1}$, Erik Slingerland ${ }^{2}$, Micael Beun ${ }^{2}$, Ruben De Winne ${ }^{3}$, Laura Pol ${ }^{1}$ and Laurie van Reemst ${ }^{1}$

${ }^{1}$ Wageningen University \& Research, Department of Environmental Sciences, the Netherlands

${ }^{2}$ IFDC, National Office Bujumbura, Burundi

${ }^{3}$ Oxfam Novib, The Hague, the Netherlands

\section{Abstract}

Stopping land degradation is one of the biggest challenges worldwide and particularly in Burundi, which currently faces unprecedented rates of soil loss and food insecurity. This paper proposes a different development discourse on how to stop land degradation, and presents results and lessons learned of a bottom-up inclusive 
approach implemented since 2014 in Burundi: the Integrated Farm Planning approach (PIP) approach. This approach aims to build a solid foundation for sustainable change towards enhanced food production and good land stewardship, based on three foundation principles (motivation, stewardship and resilience) and three guiding principles (empowerment, integration and collaboration). Findings from an impact study on the PIP approach and testimonies of farmers from a qualitative study show profound changes in land management practices and diversity of activities on the farm, as well as in the social cohesion in households and villages. Based on a vision and a plan, nearly 80,000 motivated households are currently actively involved to stop land degradation and make their farms more productive, while in all PIP villages concrete collective action is undertaken for sustainable land stewardship. Given that these actions are widespread and come along with a change in mind-set rooted in all three foundation principles, the paper concludes that the PIP approach is able to effectively build a foundation for sustainable change. Five key lessons from this experience reveal the key elements of a different development discourse that actually motivates and mobilises farmers to stop land degradation.

\section{Key words}

Land degradation - Land stewardship - PIP approach - Mobilising farmers - Burundi

\section{Introduction}

With globally $33 \%$ of soils considered degraded (UNCCD, 2017), stopping land degradation while sustainably producing food is one of the biggest challenges worldwide (Bouma \& McBratney, 2013; Diamond, 2005; Webb et al., 2017). This challenge is particularly pressing in a country like Burundi, which depends on subsistence farming on often steep slopes, and where the population size will double towards 2040. Already at present, with a population density of $450 / \mathrm{km}^{2}$, high pressure on the land combined with unsustainable agricultural practices is leading to wide-scale deforestation, over-exploitation of the land, and soil erosion (Eggers, 2006). Burundi scores second lowest worldwide on the Global Food Security Index (2019), with more than 50\% of the population being chronically food insecure (WFP, 2019) and unable to meet their dietary needs (Niragira et al., 2015). Although soil erosion and its effect on crop yields are not new phenomena in this region (Dregne, 1990), current rates and scale of erosion are unprecedented, and urgent action is required to prevent the permanent loss of ecosystem services due to land degradation (Blake et al., 2018).

The question is what strategies can reverse land degradation and declining food security? Burundi has received considerable international development aid in the past decades, but hardly any progress was made in alleviating poverty and food insecurity. The underlying reason is that these interventions were often shortterm, top-down and focused on conflict-resolution or emergency aid (Uvin, 2010). Currently, development programmes start paying more attention to agricultural production and land degradation, but approaches often lack essential elements of sustainability, such as building local ownership, capacities and motivation. Tackling complex societal issues such as land degradation cannot be done by top-down interventions or incentive-based approaches (Hall-Blanco, 2016); because "Only the self-reliant efforts of poor people and poor societies themselves can end poverty..." (Easterly, 2006).

Hence, development actors should become facilitators of bottom-up and community-based development (Abrams et al., 2009), and enable farmers to tackle land degradation themselves. This article presents such a bottom-up approach, the Integrated Farm Planning approach, or PIP approach (in French: "Plan Intégré du Paysan"), which proposes a different development discourse on how to tackle land degradation in complex rural-oriented economies like in Burundi. After conceptualizing the PIP approach in the next sections, the paper discusses results and lessons learned, and concludes by reflecting on the applicability of the PIP approach to stop land degradation and move towards resilience-based stewardship. 


\section{Building a foundation for sustainable change}

Burundi is endowed with abundant rainfall, fertile arable land, and productive marshlands. With a population growth of $3.3 \%$ and with $87 \%$ of the population living from small-scale agriculture, plots have continuously become more fragmented ( 0.3 to 0.5 ha per household), driving farmers to further intensify production and deplete soil fertility to the limit. Farming is mainly rainfed, with staple crops like maize, beans and cassava cultivated on steep slopes with unsustainable farming practices. Expansion of farmland and dependence on wood for fuel, has pushed deforestation, with forests currently covering only $6.6 \%$ of the territory. Erosion rates in the highlands of Burundi can reach 100 tons/ha (Ndagijimana, Kessler, \& Asseldonk, 2019), aggravated by increasingly more frequent torrential rains. The resulting loss of soil fertility and its effect on food security make better land stewardship by smallholders a top priority in Burundi.

It is in this context that the PIP approach was first introduced in Burundi in 2013, aiming to build a solid foundation for sustainable change towards enhanced food production and good land stewardship. The PIP approach considers that first investing in the people and the land they manage - before investing in anything else - is a precondition for sustainable change. The household level is therefore central to motivate farmers to invest in their land, but by facilitating farmer-to-farmer trainings and knowledge exchange, tackling land degradation at community and landscape level is one of the final goals (Kessler, van Duivenbooden, Nsabimana, \& van Beek, 2016).

How the PIP approach works can best be visualized as in Figure 1. Just like a tree that needs fertile soil to grow strong, the PIP approach builds a foundation for sustainable change based on three principles: motivation, stewardship and resilience. This foundation, of genuinely motivated stewards of the land and its natural resources, is essential for the sustainability of any intervention or action. This is illustrated by the arrow in the trunk of the tree, which points to activities such as livestock improvement, reforestation, value chain development, water projects, and micro-credit schemes. Where this foundation is lacking, interventions will face limited ownership and often fail to achieve sustainable results (Easterly, 2006; Oino, Towett, Kirui, \& Luvega, 2015).

Within the PIP approach 'resilience-based stewardship' is a key concept, in which these three foundation principles come together. Based on (Chapin et al., 2011), who use this concept as a framework for stewardship strategies that can increase social-ecological resilience, we define resilience-based stewardship as "motivated stakeholders who feel responsible to be good stewards of the land and its natural resources, and invest in social-ecological resilience of their landscape". Furthermore, the blue outer circle of Figure 1 presents the three guiding principles of the PIP approach: empowerment, integration and collaboration. During implementation of any activity it is crucial (especially for project staff) to empower people, to foster integration of activities, and to enhance collaboration to scale-up faster. This mobilization of farmers to collaborate is essential to stop land degradation, and is illustrated by the branches of the tree where the process starts at household level, spreads to community level and eventually covers a whole landscape.

Creating an Integrated Farm Plan (a PIP) at household level is a key tool in the approach. This PIP creation, in which family members develop a vision and an action plan together, is a flywheel for all other changes that follow. Figure 2 gives an example of a PIP as drawn by a family, with left the current situation and right the desired future farm in 3-5 years, including erosion control measures, a diverse crop-livestock system, compost pits, a vegetable garden, and agroforestry. By creating a PIP together, awareness grows within families about the importance of integrated farm planning and limiting social and intra-household issues. These dialogues on possibilities to improve, reach attainable goals, and how to define this in a PIP, lead to better organized households with common objectives. What follows is motivated action, because a PIP is based on households' own capabilities and knowledge, and not on project targets or objectives. These PIPs at household level are the first pieces of the required foundation for sustainable change, with further upscaling of PIP being essential to stop land degradation at village and beyond.

At village level, upscaling PIP creation takes about 2 years, with a key role for Farmer Innovators, who are (fe)male farmers - chosen by the community itself - with a progressive mind-set and spirit to improve. They 
are the first to create a PIP, then become PIP trainers, and through farmer-to-farmer training - mainly in competitions between organized groups - build capacities in the rest of the community; with ever more households becoming motivated stewards of their land. This is strengthened by exchange visits and the development of Village Visions, which are concrete plans for diverse collective activities, better access to markets, landscape restoration, and organized village structures. Local institutions and extension workers are closely involved in all activities, given that their motivation and genuine engagement are essential for ownership of the key elements of the PIP approach and for the sustainability of all actions.

\section{Foundation principles of the PIP approach}

This section conceptualizes the three foundation principles of the PIP approach - motivation, stewardship and resilience - and how they are used and stimulated in the approach to build the foundation for sustainable change.

\section{Motivation}

In its most basic form, motivation is an inspiration or impetus to act (Ryan \& Deci, 2000). Being of pivotal importance for actors in carrying out tasks, motivation can originate from a variety of sources. A distinction is often made between intrinsic and extrinsic motivation. Intrinsic motivation refers to doing something because it is inherently satisfying or enjoyable, based on an actor's internal interest (Ryan \& Deci, 2000). It relates to intrinsic life goals, and is driven by feelings of autonomy, competence and relatedness (Deci \& Ryan, 2008a). Extrinsic motivation is characterized by external incentives (e.g. rewards or avoided punishments) to accomplish something, and may even be counterproductive to intrinsic motivation (Bhaduri \& Kumar, 2011; Ryan \& Deci, 2000). Intrinsic motivation is most crucial for sustainable change, i.e. motivation which is autonomous and leads to ownership and genuine engagement in an activity (Vansteenkiste, Simons, Lens, Sheldon, \& Deci, 2004).

Motivation in the PIP approach is about creating ownership and avoiding that farmers undertake action because of an external reward (like money or in-kind incentives). It is stimulated from the start, when during PIP creation - based on their needs and aspirations - families draw their future vision. Developing a vision provides motivation to act (Greiner \& Gregg, 2011) and visualizing an attainable future gives people an increased sense of purpose. This is related to self-reliance, with people feeling competent to achieve something and actively search for solutions. This autonomous motivation which comes from internal sources (Deci \& Ryan, 2008b) is a strong motivator for good stewardship (Ryan, Erickson, \& De Young, 2003). Furthermore, social capital aspects such as trust, collaboration and reciprocity have a positive effect on the motivation of people to manage natural resources collectively (Pretty, 2003), including concrete action to stop soil erosion.

\section{Stewardship}

Stewardship refers to our responsibility to manage and protect the land and its natural heritage

(Brown \& Mitchell, 1998), and involves nourishing something for someone else: for society, nature, a God, or future generations (Worrell \& Appleby, 2000). Stewardship is therefore essentially different from traditional management methods, given that the latter are more focused on efficiency and profitability, while stewardship is more acting for a benevolent purpose, as a moral duty or responsibility. It is based on the premise that "pro-organizational, collectivistic behaviours have higher utility than individualistic, self-serving behaviour" (Davis, Schoorman, \& Donaldson, 1997). Stewardship also refers to shaping pathways towards ecological resilience, especially in the context of social-ecological systems such as farming systems (Chapin et al., 2011; Kofinas \& Chapin, 2009); as such building further on elements of resilience thinking.

In the PIP approach stewardship is stimulated by creating awareness about changes in natural resources and our own role, inducing the responsibility in stakeholders to protect and conserve land, water and vegetation. This is closely related to awareness about environmental values, such as prevention of pollution, protection of the environment, respect for the earth and unity with nature; also referred to as biospheric values (Steg, 
Perlaviciute, Van der Werff, \& Lurvink, 2014). However, stewardship is only valuable when translated into concrete actions. Hence, in the PIP approach, during a series of workshops where farmers exchange knowledge and experiences and receive on-demand trainings, stewardship is further strengthened with capacity building on good practices related to land and farm management and use of the commons.

Resilience

Resilience is frequently described as the ability of a system to return to its initial state after a shock or perturbation (Holling, 1973). This implies the system - in our case the farm or the village with their physical and social components - to be adaptive, subject to change, and consisting of interacting subsystems (Rammel, Stagl, \& Wilfing, 2007). Each subsystem directly responds to external shocks or other changes, but since subsystems interact, one may also respond to modifications of another subsystem. Resilience thinking thus moves away from 'traditional' analytical assumptions such as linearity and predictability (Darnhofer, Fairweather, \& Moller, 2010; Scoones et al., 2007), towards dynamics of complexity within a system. Therefore, a paradigm shift is required from an emphasis on efficiency or production of a (farming) system, to adaptability, capacity development and evidence-based learning (Darnhofer et al., 2010).

Resilience within the PIP approach implies focusing both on physical aspects of farming, as well as coping capacities of households and villages. Diversification of crops, income sources and practices are particularly important, given land scarcity for agriculture and vulnerability to climatic risks. Including non-farm income sources, high-quality cash crops and livestock in the farming system as an income source, is therefore always stressed during PIP creation. Concerning social resilience, coping strategies and adaptive capacities of families are particularly crucial, in terms of education, skills, knowledge, health and organisation (Ellis, 1998; Keck \& Sakdapolrak, 2013). The PIP approach continuously stresses these elements of social resilience, and also builds with its activities social cohesion within families and in villages.

\section{Guiding principles of the PIP approach}

The three guiding principles conceptualized in this section - empowerment, integration and collaboration aim at organisations and staff involved in the PIP approach, and how they work with local actors. Rather than extension agents transferring knowledge, PIP staff arefacilitators of change; and farmers, rather than beneficiaries of a project, are agents of change. In this bottom-up process, PIP staff creates a level playing field with other stakeholders, with the three guiding principles enabling resilience-based stewardship to become firmly rooted in the foundation.

\section{Empowerment}

Empowerment is a concept in which individual competencies and proactive behaviour are linked to social change processes (Perkins \& Zimmerman, 1995; Rappaport, 1981). Empowerment theory stresses the need to increase personal, interpersonal and political power of communities, as to foster collective action to improve their environments (Lee, 2011) At the individual level, empowerment concerns a process in which people gain control over their lives, develop a sense of self-determination, and eventually believe in their capability to change their own realities (Fetterman, 2017; Gutierrez, 1990; Rappaport, 1981). Furthermore, for actors going through the empowerment process, it entails making decisions themselves rather than embracing externally raised recommendations (Friis-Hansen \& Duveskog, 2012). At the collective level, empowerment means that collaborating with others enables achieving goals faster.

Empowerment in the PIP approach is therefore related to the concept of "conscientization" (Freire, 1972), which is the process of people becoming aware about their ability to transform reality by conscious collective action. This is crucial, because creating a vision and a plan, combined with the on-demand trainings and group dynamics, empowers farmers to act. Empowerment as a guiding principle in the PIP approach implies that it is a core attitude of all staff to devolve power to local actors and enhance their ownership. Hence, PIP staff should always work on empowering local actors to do it themselves . Furthermore, by empowering local 
actors, the PIP approach constantly strengthens the foundation for sustainable action, and builds an evergrowing movement of actors of change who believe in their ability to improve their life and the environment; first of all land.

\section{Integration}

In relation to rural livelihoods, integration refers to an interdisciplinary system-wide approach in which components of human and agro-ecological systems are taken into account(Horton et al., 2017). When used for natural resource management, integration also has a spatial connotation, by considering the watershed or farm as a system where 'integrated management' is required to optimize synergies and make the system more robust and resilient. This is crucial also for land degradation processes, particularly for soil erosion, where bad land management upstream affects land users downstream. Furthermore, integration fosters the ability to cope with fluctuations in environmental or economic circumstances (Gautam \& Andersen, 2016). Diversification is therefore a crucial element of any integrated strategy, given that diversified livelihood systems appear more resilient than undiversified ones (Bosma, Udo, Verreth, Visser, \& Nam, 2005).

Integration is a guiding principle throughout the PIP approach and particularly during PIP creation, with integration and diversification of activities and practices in the household and on the farm being essential. However, integration also works in the social dimension of the approach, in which people value multi-ethnicity, foster personal diversity and build social cohesion, while becoming eager to learn from others. The PIP approach stimulates to continuously seek for diversity, opportunities and innovations; hence, similarly to empowerment, PIP staff should have integration present during all their work, and stimulate farmers and other actors to always learn more, do better, and experiment with new activities and practices.

\section{Collaboration}

Given that natural resource conflicts are often related to increased scarcity of resources, unequal access and off-site effects, they cannot be solved by strict control (Buckles \& Rusnak, 1999). Collaboration is therefore crucial in addressing natural resource management issues, particularly also in relation to climate change. However, collaboration requires sound processes of governance (Agarwal, 1997), long-term associations and an atmosphere of trust (Palis, 2006), as well as social conditions that enable actors to share information and learn from each other (Schneider, Fry, Ledermann, \& Rist, 2009). Collaboration therefore refers to joint activities and the exchange of knowledge as part of strengthening social relations and networks. Bonding social capital (between people with similar objectives) and binding social capital (the capacity to link with others) are crucial aspects of collaboration, and beneficial for joint investments in natural resource management (Pretty, 2003).

Because of being so fundamental to the PIP approach, collaboration is stimulated in all activities at all levels: in workshops with the Farmer Innovators, in each family designing a PIP, in the farmer-to-farmer group trainings, etc. Similar to the previous two guiding principles, seeking collaboration with other people and organisations should be a life attitude of staff working with the PIP approach. Particularly important is to establish trust and to continuously exchange information, which are both reciprocal actions built on equal and mutual connections (Borg, Toikka, \& Primmer, 2015). This again emphasizes the role of PIP staff as facilitators of a process in which they build a coalition of actors of change, particularly farmers, to foster PIP and mobilize people at a large-scale.

\section{Results and impact of the PIP approach}

The PIP approach was first used in 2014 by the SCAD11SCAD project, financed by RVO and Achmea Foundation from the Netherlands (2014-2017) project in three provinces. Since 2016 the PAPAB22PAPAB project, financed by the Dutch Embassy in Burundi (2016-2020) project has implemented the approach in another six provinces, covering currently 266 villages and nearly 80,000 PIP households. Considerable changes are noticeable in these villages, not only on the farms and concerning land stewardship, but also 
within the PIP households and at village level, with more social cohesion and intensified collaboration. In order to better quantify these changes and understand farmers' perspectives, two studies were conducted in 2018: an impact study' and a qualitative evaluation. This section presents the main results of both studies.

\section{Methods}

The impact study covered 202 randomly selected households in villages of the SCAD project. The sample was taken from four generations of PIP farmers: the $1^{\text {st }}$ generation are Farmer Innovators trained by the project in 2014/15; the $2^{\text {nd }}$ and $3^{\text {rd }}$ generations are trained by farmer-trainers in two consecutive PIP competitions $(2015 / 16)$; and the $4^{\text {th }}$ generation is from adjacent villages where the PIP approach was recently scaled-up (2017). A control group (non-PIP) was taken from villages where the approach was not implemented. Among the interviewees $60 \%$ were male and $40 \%$ female.

The qualitative evaluation was conducted among 30 PIP farmers who had started PIP creation in 2016/17 with the PAPAB project, and were purposively selected to capture a diverse set of opinions and experiences. The sample was proportionally spread over three generations of PIP farmers, both sexes, and all six PAPAB provinces. Using the Most Significant Change methodology, interviews focused on 1) changes in behaviour, attitude, and way of living; 2) changes in intrinsic motivation; and 3) changes in collaboration and decisionmaking within the household.

\section{Impact on land and farms}

Land stewardship and implementing better and more diverse conservation practices is central in the PIP approach. Figure 3 presents for different PIP generations11Responses of non-PIP farmers on this question could not be checked in the field and are left out the change in use - before and after PIP creation - of four key conservation practices: compost pits (with a roof, well managed), agroforestry (trees on the farm), contour trenches (slow-forming terraces with vegetation on the bund) and mulching (mainly for perennials). Figure 3 shows that most of the $1^{\text {st }}$ generation PIP farmers currently using all four practices. This percentage gradually decreases for later generations, where it is remarkable that the $4^{\text {th }}$ generation adopts conservation practices very fast after having created their PIP. These farmers from adjacent villages are often farmers who have heard about PIP from their fellow farmers in initial PIP villages, and are eager to start as well.

Particularly important for erosion control are trenches on the contour, which require considerable effort and labour, but are nevertheless quickly adopted by almost all PIP farmers. The same applies to the integration of trees on the farm, which is done by about $30 \%$ of the farmers before they start with PIP, but currently by more than $90 \%$ of them. Similar trends of fast uptake by PIP farmers is also seen for other practices such as contour ploughing, crop rotations, staggered row planting (especially for banana trees), and the use of vegetable gardens. This integration of a diversity of conservation practices on a field is essential for restoring soil fertility and reducing soil losses, and contributes to farm resilience. Farmers experience these changes and appreciate the trainings and the knowledge they have gained, as expressed in the qualitative evaluation by this second generation PIP farmer:

"With the PIP approach, I feel able to prepare for my future because I have received the whole technical package to increase agricultural production. [...] Even if the project stops today we will still continue because the knowledge we have received from the project is sufficient for the implementation of our PIP. The PIP has developed us a lot, we can't stop."

Gaining the technical knowledge to implement and maintain conservation practices is crucial for sustainable land management. In the PIP approach this is mainly done from farmer-to-farmer and on the farms, allowing as such that - next to agro-technical knowledge - farmer trainers exchange their experiences, vision and inspiration. Figure 4 shows how different PIP generations rate the knowledge they have gained over the past years for a variety of crop and land management practices. Non-PIP farmers score close to zero for all practices, meaning that even some basic agricultural practices such as good planning of crop rotations and contour ploughing seem to be unknown to them. This changes rapidly after the PIP trainings, with the $1^{\text {st }}$ and $2^{\text {nd }}$ generations affirming to have acquired (much) more knowledge on all practices, and $3^{\text {rd }}$ and $4^{\text {th }}$ 
generations scoring just a bit lower. PIP farmers quickly become eager to learn from others and start actively approaching farmers who know more (see quote below of a $3^{\text {rd }}$ generation PIP farmer of 65 years old). This scaling process is driven by the different mind-set of these farmers after PIP creation and their awareness of land stewardship.

"At village level, the PIP approach is the basis for collaboration between community members, and as a third generation PIP farmer I make household visits to other generations of PIP farmers to ask them for technical advice. They do so with pleasure, something that was not done before PIP."

Increased diversity on PIP farms is noticed by the number of crops, with PIP farmers having 16-19 different perennial, annual and vegetable crops on the farm, while non-PIP farmers have only 12. More vegetables and some extra perennial crops contribute to this difference, with the increased use of kitchen gardens as an important driver. Some of the new crops are cash crops, and income from cash crops has increased by 85-100\% for all PIP generations. Noteworthy too is that PIP farmers, in particular those working longer with PIP, invest significantly more in livestock than non-PIP farmers, especially in cows and goats. Livestock keeping is an important element of farm resilience and is now being more frequently integrated on PIP farms.

Impact on people and households

About $90 \%$ of all PIP farmers in the impact study affirm that they are more willing to stay in the village than 3 years ago. A similar percentage considers that living and farm conditions have improved after having created a PIP, with an income increase not only from cash crops but also from off-farm activities and entrepreneurial initiatives. Furthermore, PIP farmers explain in testimonies that due to their new spirit to develop and invest in their future, they have better access to financial capital (credits). The assessment of farmers' recent investments shows that the $1^{\text {st }}$ generation is most successful in generating more income. However, also other PIP generations improve their living conditions, as this $2^{\text {nd }}$ generation PIP farmer explains:

"Currently in my household, following a good climate of understanding between my wife and children, with the creation of our PIP we are very healthy. We produce enough, we eat to our satisfaction with variations [...]. The school fees of 5 children and health care expenses for all members of my family are covered. We live in a house of which I have renewed the roof with 30 metal sheets purchased from the income generated by agriculture and savings groups."

Results furthermore show that PIP households are considerably more food secure than non-PIP farmers in the months after the important bean-producing season (July-September), and are able to keep their stock of produce for a longer period. Non-PIP farmers are back on the food security level of "we can just manage" already in September, while half of the PIP farmers remains until December on the level of "we have enough to eat". The flywheel effect of working with PIP and becoming more food secure, also through new off-farm activities, is testified by this $3^{\text {rd }}$ generation female PIP farmer:

"This small business I started with PIP in addition to farming has allowed us to increase household incomes and change the diet. For this reason, the disputes in our household have totally disappeared because the cause was poverty and the lack of consultation on the different activities to be done."

The previous quote also shows how creating a PIP has changed household dynamics, and triggers families to start implementing their planned activities. Results from the impact study indicate that more than $50 \%$ of the $3^{\text {rd }}$ and $4^{\text {th }}$ generation PIP farmers are within a year already halfway the implementation of their PIP. This is above all the result of how motivated PIP farmers with a different mind-set transmit their passion to others. This is what drives the scaling-up of the PIP approach, and as such joint efforts stop land degradation:

"At the community level, our family has engendered a more harmonious understanding in other households, after they had heard my wife's testimony about how she has changed. The other households were surprised because of this radical change in behaviour. Now she is the one who is mobilizing other households to adhere to the PIP approach because she has lessons to share. In fact, the community calls us 'the PIP household'." $\left(2^{\text {nd }}\right.$ generation PIP farmer) 
In order to assess motivation, responses by farmers on a set of open questions concerning their future prospects, concrete objectives for the farm and planned investments, were converted into a "motivation score" for each household. Although subjective and based on the what farmers tell, Figure 5 shows a clear pattern of gradually declining motivation from the first to the fourth generation, being lowest among non-PIP farmers. This motivation score was found to correlate with e.g. diversity of land management practices and crop diversity, which shows that working on both aspects together (land and people, as the PIP approach does) is essential.

The qualitative evaluation confirms that the PIP approach has a positive effect on the intrinsic motivation of PIP farmers, especially on their sense of competence to implement their PIP and the planned farm/land practices, as well as on their sense of purpose towards this plan. PIP farmers also often express that they are proud of what they achieve and feel more esteemed than before, both within the household and in the village, resulting in more collaboration and exchange of knowledge. This is nicely expressed by this $2^{\text {nd }}$ generation PIP farmer:

"The training I received helped me to start helping my wife. When I am working with her in the field, not only do labour costs decrease but my wife is proud of my presence and I manage to provide advice on the organization of our work."

These inter-household improvements in relations between the family members are definitely a key result of the PIP approach. Good relations and understanding within a household foster social resilience and are the basis for developing all kind of activities together. In that sense the following testimony of a 25-year old lady from the third generation of PIP farmers expresses clearly what the process of PIP creation is able to do:

"With the problem tree, I identified what was wrong in my household: the lack of dialogue, mismanagement of household assets, lack of vision and planning, and my husband who loves alcohol a lot and leaves all activities to me. [...] With the solution tree, [I realize] we should improve family dialogue, break the fear of talking to my husband, and share the new knowledge acquired with him, because the PIP is not individual, it is a household PIP."

\section{Lessons learned for a different discourse}

Results from both studies show the enormous potential of the PIP approach to mobilise farmers to stop land degradation and move towards resilience-based stewardship. Widespread conservation practices, better managed farms, enhanced food security, organized villages and farmers who are motivated to invest in their farm; these are all signs that the approach works. Results also suggest that the three foundation principles of the PIP approach - if developed and given attention from the start - mutually reinforce each other, with notably motivation driving stewardship (Ryan et al., 2003). By envisioning the future, planning activities together and seeing quick results, farmers realize that good land stewardship improves yields and food security, and become more resilient in all respects (knowledge, income, diversity, social relations, etc.). This change in mind-set and the rapidly growing sense of responsibility for better stewardship (Brown \& Mitchell, 1998 ) is the crux of the PIP approach, and explains why even in the $3^{\text {rd }}$ and $4^{\text {th }}$ generation PIP farmers who only recently created their PIP - effects are already visible.

Furthermore, the fact that everyone, even poor or illiterate families, are able to envision, draw, plan and implement practices according to their needs and capabilities, is an important reason for the fast uptake of PIP creation. The same applies to women, who are often among the best Farmer Innovators and trainers. Empowerment is the main guiding principle during trainings, and makes farmers more self-reliant, creates ownership and as such drives motivated action. Together with collaboration, empowerment also works at group and village level, triggering 'conscientization' which is essential in a process of transformation (Freire, 1972). For instance, only facilitating that information flows within the group of Farmer Innovators is already sufficient to start action, as they learn from others, realize that solutions are within reach, and feel able to do it themselves - and even faster with others. This is also observed in the process of Village Vision development, which is currently on-going in most PIP villages as a follow-up step to PIP creation at household level. 
Collectively, all kinds of action are undertaken to dig trenches, construct roads and plant trees. This is in high contrast with the usual wait-and-see mentality in Burundi, which is often due to incentive-based intervention strategies that undermine the power and initiative of farmers to act.

Working along the guiding principles of empowerment and collaboration is thus crucial. Farms in Burundi are extremely small, and as farmers usually don't see any option to make a living from their land, investing in conservation practices is not a logical choice. This changes when the so-called 'PIP fever' starts spreading in a village, with PIP farmers telling others - thanks to enhanced social capital (Pretty, 2003) - how they have improved their farms and living conditions with their own means. These farmers have a different mind-set, are proud of what they have achieved, and are eager to pass the message that good land stewardship can actually enhance food production with relatively little extra effort. This attitude, this sense of stewardship and motivation to improve, are the core ingredients of a different development discourse on how to mobilize the huge number of farmers needed to stop land degradation at scale.

The third guiding principle, integration, is an inherent aspect of the PIP approach. The results and testimonies show how PIP farmers currently understand the importance of integration on their farm, and apply more diverse land and crop management practices, keep different livestock, and include cash crops and some income-generating activities. In all generations does PIP creation result in more diversified and resilient livelihoods, which is the essence of any integrated strategy (Ellis, 2000). Again, this goes along with enhanced collaboration, within the household (as many testimonies show) but also within entrepreneurial groups that have emerged and established market linkages to sell their produce collectively. That integration is understood and acted on is also visible in the initiatives that many villages are currently undertaking to collectively manage whole slopes to stop erosion.

Several lessons learned for a different discourse on how to stop land degradation in Burundi have already been mentioned in this paper. They all relate to the importance of the guiding principles for any intervention strategy, and the need to work simultaneously on all foundation principles; if not all efforts will be in vain. The five key lessons learned from the experiences in Burundi over the past six years can be summarized as follows:

1. Empowering people drives change : the PIP approach facilitates that people become actors of change, by taking their capacities and knowledge seriously, by telling them a different "story" than other projects, and by changing mind-sets towards motivated action.

2. Development starts at household level : the PIP approach facilitates households to visualize their common vision in a drawing and a plan, based on needs and aspirations of all family members, as such stimulating equity, togetherness and concrete joint action.

3. Tangible improvements on the farm are key : the PIP approach generates visible effects and shortterm gains, by facilitating that knowledge flows from farmer-to-farmer, based on better planning and integration of practices, as such stimulating good land stewardship.

4. Mobilising people creates impetus : a crucial asset of the PIP approach is its potential to scale-up and mobilise whole villages, where collaboration, social cohesion and trust grow, and people genuinely participate in PIP activities and collective action.

5. Impact requires engagement at all levels : in order to achieve impact, the PIP principles are equally needed in and applicable to staff of (implementing) organisations and (local) authorities, who need to become engaged and provide enabling conditions for impact.

\section{Conclusions}

This paper started with the question how to tackle land degradation at a wide scale in Burundi, and expressed the need to work from the bottom-up with an inclusive approach that empowers and mobilizes farmers to undertake action. A similar plea that "sustainable soil and water conservation must not impose models or packages but rather become a process for learning and perpetual novelty" was expressed already by (Pretty \& Shah, 1997), but has hardly been taken into account since then. If only that had happened, because our 
findings show that the PIP approach is able to empower and motivate up till $80 \%$ of the households in a village to invest in conservation practices on their farms and collectively at village level. These conservation efforts go hand in hand with numerous other - often profound - changes in villages that work with the PIP approach, with most PIP farmers having become more self-reliant, proud, collaborative, and progressdriven. Visualizing a more resilient and productive future farm in a drawing and planning actions within the household, has given these families new purpose and a clear direction for motivated action. Families and entire villages have changed from being passive and aimless, to being active and motivated; a clear sign of sustainable change.

Developing the three PIP foundation principles conceptualized in this paper has driven this change, with motivation - next to stewardship and resilience - being most crucial for creating ownership and genuine engagement. This requires to refrain from the use of incentives like cash and food for work, right from the start and at any time. This is a major challenge for the modus operandi of most (development) organizations, but in order to achieve sustainable impact they must become facilitators of change. In Burundi this change started at the household level, but quickly resulted in collective actions of all sorts at village level. This potential of the PIP approach to achieve impact at scale is essential to stop land degradation, with particularly the farmerto-farmer exchange of knowledge and passion for PIP creation being the flywheel. Following Hall-Blanco (2016), projects and agricultural extension services must therefore abolish traditional top-down intervention and incentive-based approaches, and must urgently join efforts to build a foundation for sustainable action by farmers themselves.

It is this change in attitude within staff and institutions that underpins the different discourse on how to stop land degradation that we propose in this paper. The challenge to empower and mobilize the millions of smallholder farmers to undertake action, can only be tackled once development organisations, institutional donors and government agencies act upon this different discourse, and when all of them have a clear vision about the need to move towards resilience-based stewardship; from farms, to villages to landscapes. Although just started, Burundi is on its way to stop land degradation, supported by ever more institutional stakeholders who see that this is the way forward. Our final plea is to learn from what is being done in Burundi, because the core elements of the PIP approach are applicable wherever there is an urgency to create more stewardship for the Earth and its natural resources.

\section{References}

Abrams, R. W., Anwana, E. D., Ormsby, A., Dovie, D. B., Ajagbe, A., \& Abrams, A. (2009). Integrating topdown with bottom-up conservation policy in Africa. Conservation Biology, 23 , 799-804. doi:10.1111/j.15231739.2009.01285.x

Agarwal, B. (1997). Environmental action, gender equity and women's participation. Development and change, 28 , 1-44. doi:10.1111/1467-7660.00033

Bhaduri, S., \& Kumar, H. (2011). Extrinsic and intrinsic motivations to innovate: tracing the motivation of 'grassroot'innovators in India.Mind \& Society, 10 , 27-55. doi:10.1007/s11299-010-0081-2

Blake, W. H., Rabinovich, A., Wynants, M., Kelly, C., Nasseri, M., Ngondya, I., . . . Boeckx, P. (2018). Soil erosion in East Africa: an interdisciplinary approach to realising pastoral land management change.Environmental Research Letters, 13 , 124014. doi:10.1088/1748-9326/aaea8b

Borg, R., Toikka, A., \& Primmer, E. (2015). Social capital and governance: a social network analysis of forest biodiversity collaboration in Central Finland. Forest Policy and Economics, 50 , 90-97. doi:10.1016/j.forpol.2014.06.008

Bosma, R. H., Udo, H. M., Verreth, J. A., Visser, L. E., \& Nam, C. Q. (2005). Agriculture diversification in the Mekong Delta: farmers' motives and contributions to livelihoods. Asian journal of agriculture and development, 2 , 49-66. doi:10.22004/ag.econ.165780

Bouma, J., \& McBratney, A. (2013). Framing soils as an actor when dealing with wicked environmental 
problems. Geoderma, 200 , 130-139. doi:10.1016/j.geoderma.2013.02.011

Brown, J. L., \& Mitchell, B. A. (1998). Stewardship: a working definition. Environments; Waterloo, 26 , 8.

Buckles, D., \& Rusnak, G. (1999). Conflict and collaboration in natural resource management. In D. Buckles (Ed.), Cultivating Peace: Conflict and Collaboration in Natural Resource Management, 1-12. Ottawa, ON, Canada: IDRC/World Bank. Ottawa, Canada: International Development Research Centre.

Chapin, F. S., Pickett, S. T., Power, M. E., Jackson, R. B., Carter, D. M., \& Duke, C. (2011). Earth stewardship: a strategy for social-ecological transformation to reverse planetary degradation. Journal of Environmental Studies and Sciences, 1 , 44-53. doi:10.1007/s13412-011-0010-7

Darnhofer, I., Fairweather, J., \& Moller, H. (2010). Assessing a farm's sustainability: insights from resilience thinking. International journal of agricultural sustainability, 8 , 186-198. doi:10.3763/ijas.2010.0480

Davis, J. H., Schoorman, F. D., \& Donaldson, L. (1997). Toward a stewardship theory of management. Academy of Management review, 22 , 20-47. doi:10.5465/amr.1997.9707180258

Deci, E. L., \& Ryan, R. M. (2008a). Facilitating optimal motivation and psychological well-being across life's domains. Canadian psychology/Psychologie canadienne, 49 , 14. doi:10.1037/0708-5591.49.1.14

Deci, E. L., \& Ryan, R. M. (2008b). Self-determination theory: A macrotheory of human motivation, development, and health. Canadian psychology/Psychologie canadienne, 49 (3), 182. doi:10.1037/a0012801

Diamond, J. (2005). Collapse: How societies choose to fail or succeed. New York, USA: Penguin Books.

Dregne, H. (1990). Erosion and soil productivity in Africa.Journal of Soil and Water Conservation, 45 (4), 431-436.

Easterly, W. R. (2006). The White Man's Burden . New York: The Penguin Press.

Eggers, E. K. (2006). Historical dictionary of Burundi (3rd ed.). Plymouth, UK: Scarecrow Press, Inc.

Ellis, F. (1998). Household strategies and rural livelihood diversification. The journal of development studies, 35 , 1-38. doi: $10.1080 / 00220389808422553$

Ellis, F. (2000). The determinants of rural livelihood diversification in developing countries. Journal of agricultural economics, 51 , 289-302. doi:10.1111/j.1477-9552.2000.tb01229.x

Fetterman, D. M. (2017). Empowerment Evaluation: Linking Theories, Principles, and Concepts to Practical Steps. In C. Secolsky \& D. B. Denison (Eds.), Handbook on Measurement, Assessment, and Evaluation in Higher Education (pp. 529-541). New York, USA: Routledge.

Freire, P. (1972). Pedagogy of the oppressed . Hamondsworth, UK: Penguin Books.

Friis-Hansen, E., \& Duveskog, D. (2012). The empowerment route to well-being: An analysis of farmer field schools in East Africa.World Development, 40 , 414-427. doi:10.1016/j.worlddev.2011.05.005

Gautam, Y., \& Andersen, P. (2016). Rural livelihood diversification and household well-being: Insights from Humla, Nepal. Journal of Rural Studies, 44 , 239-249. doi:10.1016/j.jrurstud.2016.02.001

Global Food Security Index (2019). Global Food Security Index. Retrieved from https://foodsecurityindex.eiu.com/Index

Greiner, R., \& Gregg, D. (2011). Farmers' intrinsic motivations, barriers to the adoption of conservation practices and effectiveness of policy instruments: Empirical evidence from northern Australia.Land use policy, 28 , 257-265. doi:10.1016/j.landusepol.2010.06.006

Gutierrez, L. M. (1990). Working with women of color: An empowerment perspective. Social work, 35 , 149-153. doi:10.1093/sw/35.2.149 
Hall-Blanco, A. R. (2016). Why Development Programmes Fail: William Easterly and the Political Economy of Intervention. Economic Affairs, 36 , 175-183. doi:10.1111/ecaf.12174

Holling, C. S. (1973). Resilience and stability of ecological systems. Annual review of ecology and systematics, 4 , 1-23. doi:10.1146/annurev.es.04.110173.000245

Horton, P., Banwart, S. A., Brockington, D., Brown, G. W., Bruce, R., Cameron, D., . . . Jackson, P. (2017). An agenda for integrated system-wide interdisciplinary agri-food research. Food Security, 9 , 195-210. doi:10.1007/s12571-017-0648-4

Keck, M., \& Sakdapolrak, P. (2013). What is social resilience? Lessons learned and ways forward. Erdkunde , 5-19. doi:10.3112/erdkunde.2013.01.02

Kessler, A., van Duivenbooden, N., Nsabimana, F., \& van Beek, C. (2016). Bringing ISFM to scale through an integrated farm planning approach: a case study from Burundi. Nutrient Cycling in Agroecosystems, 105 , 249-261. doi:10.1007/s10705-015-9708-3

Kofinas, G. P., \& Chapin, F. S. (2009). Sustaining livelihoods and human well-being during social-ecological change. In F. S. Chapin, G. P. Kofinas, \& C. Folke (Eds.), Principles of ecosystem stewardship(pp. 55-75). New York, USA: Springer.

Lee, J. A. (2011). The empowerment approach to social work practice. In F. Turner, J. (Ed.), Social Work Treatment: Interlocking Theoretical Approaches. New York, USA: Oxford University Press.

Ndagijimana, M., Kessler, A., \& Asseldonk, M. v. (2019). Understanding farmers' investments in sustainable land management in Burundi: A case-study in the provinces of Gitega and Muyinga. Land Degradation $\mathscr{E}$ Development, 30 , 417-425. doi:10.1002/ldr.3231

Niragira, S., D’Haese, M., D'Haese, L., Ndimubandi, J., Desiere, S., \& Buysse, J. (2015). Food for survival: Diagnosing crop patterns to secure lower threshold food security levels in farm households of Burundi. Food and nutrition bulletin, 36 , 196-210. doi:10.1177/0379572115587491

Oino, P. G., Towett, G., Kirui, K., \& Luvega, C. (2015). The dilemma in sustainability of community-based projects in Kenya. Global journal of advanced research, 2 , 757-768.

Palis, F. G. (2006). The role of culture in farmer learning and technology adoption: a case study of farmer field schools among rice farmers in central Luzon, Philippines. Agriculture and Human Values, 23 , 491-500. doi:10.1007/s10460-006-9012-6

Perkins, D. D., \& Zimmerman, M. A. (1995). Empowerment theory, research, and application. American journal of community psychology, 23 , 569-579. doi:0091-0627/95/1000-0569507.50/0

Pretty, J. \& Shah, P. (1997). Making soil and water conservation sustainable: from coercion and control to partnerships and participation. Land Degradation $\mathscr{E}$ Development, 8 , 39-58. doi:10.1002/(SICI)1099145X(199703)8:1<39::AID-LDR242>3.0.CO;2-F

Pretty, J. (2003). Social capital and the collective management of resources. Science, 302 , 1912-1914. doi:10.1126/science.1090847

Rammel, C., Stagl, S., \& Wilfing, H. (2007). Managing complex adaptive systems - a co-evolutionary perspective on natural resource management.Ecological economics, 63 , 9-21. doi:10.1016/j.ecolecon.2006.12.014

Rappaport, J. (1981). In praise of paradox: A social policy of empowerment over prevention. American journal of community psychology, 9 , 121-145.

Ryan, R., \& Deci, E. (2000). Intrinsic and extrinsic motivations: Classic definitions and new directions. Contemporary educational psychology, 25 (1), 54-67. doi:10.1006/ceps.1999.1020 
Ryan, R. L., Erickson, D. L., \& De Young, R. (2003). Farmers' motivations for adopting conservation practices along riparian zones in a mid-western agricultural watershed. Journal of Environmental Planning and Management, 46 , 19-37. doi:10.1080/713676702

Ryan, R. M., \& Deci, E. L. (2000). Intrinsic and Extrinsic Motivations: Classic Definitions and New Directions. Contemporary educational psychology, 25 , 54-57. doi:doi:10.1006/ceps.1999.1020

Schneider, F., Fry, P., Ledermann, T., \& Rist, S. (2009). Social learning processes in Swiss soil protectionthe 'from farmer-to farmer'project. Human ecology, 37, 475-489. doi:10.1007/s10745-009-9262-1

Scoones, I., Leach, M., Smith, A., Stagl, S., Stirling, A., \& Thompson, J. (2007). Dynamic systems and the challenge of sustainability. Retrieved from Brighton, UK:

Steg, L., Perlaviciute, G., Van der Werff, E., \& Lurvink, J. (2014). The significance of hedonic values for environmentally relevant attitudes, preferences, and actions. Environment and behavior, 46 , 163-192. doi:10.1177/0013916512454730

UNCCD. (2017). Global Land Outlook . Retrieved from Bonn, Germany

Uvin, P. (2010). Structural causes, development co-operation and conflict prevention in Burundi and Rwanda. Conflict, Security \& Development, 10 , 161-179. doi:10.1080/14678800903553944

Vansteenkiste, M., Simons, J., Lens, W., Sheldon, K. M., \& Deci, E. L. (2004). Motivating learning, performance, and persistence: the synergistic effects of intrinsic goal contents and autonomy-supportive contexts. Journal of personality and social psychology, 87 , 246. doi:10.1037/0022-3514.87.2.246

Webb, N. P., Marshall, N. A., Stringer, L. C., Reed, M. S., Chappell, A., \& Herrick, J. E. (2017). Land degradation and climate change: building climate resilience in agriculture. Frontiers in Ecology and the Environment, 15 , 450-459. doi:10.1002/fee.1530

WFP (2019). Burundi. Retrieved from https://www.wfp.org/countries/burundi

Worrell, R., \& Appleby, M. C. (2000). Stewardship of natural resources: definition, ethical and practical aspects. Journal of agricultural and environmental ethics, 12 , 263-277. doi:10.1023/A:1009534214698 


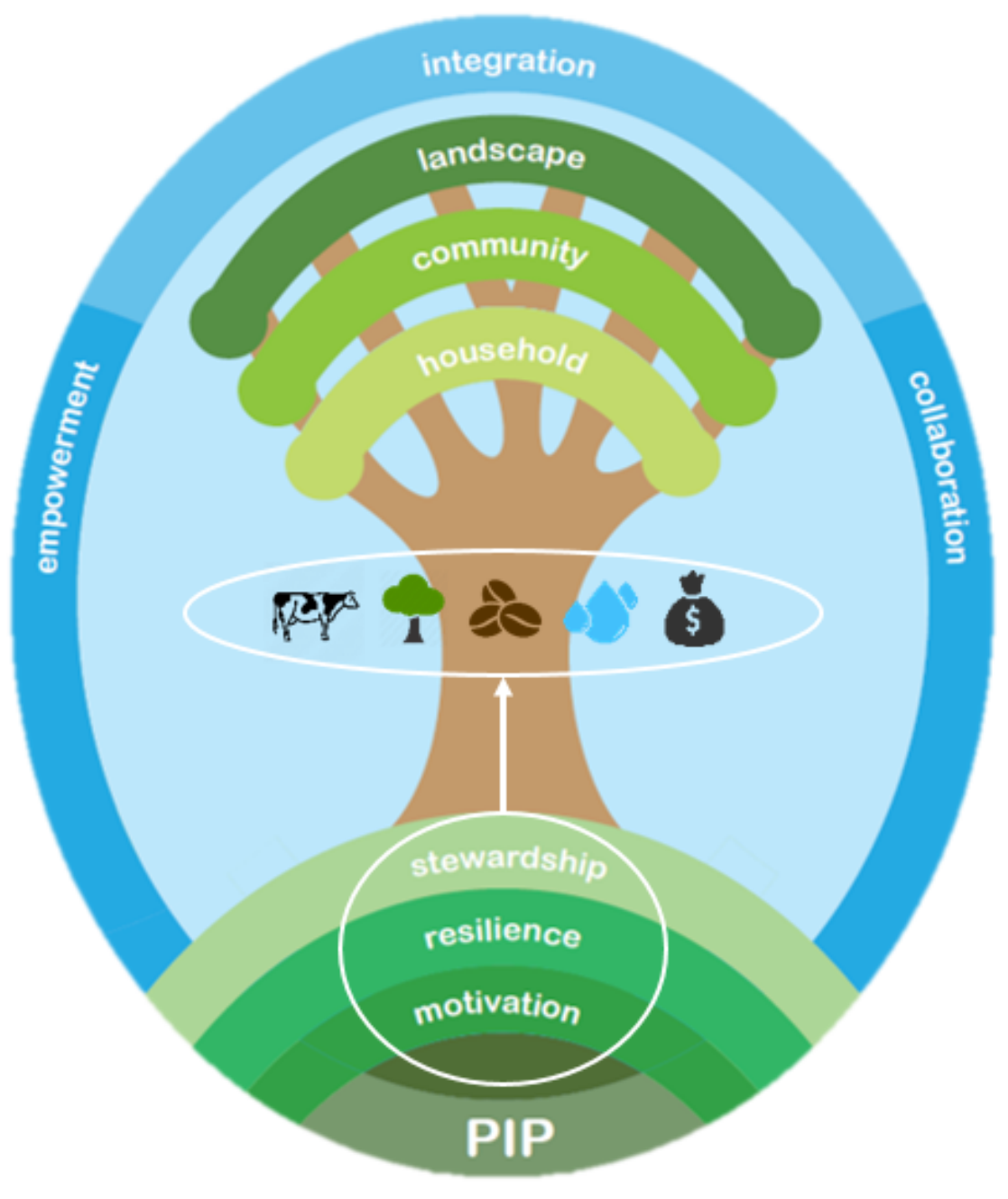



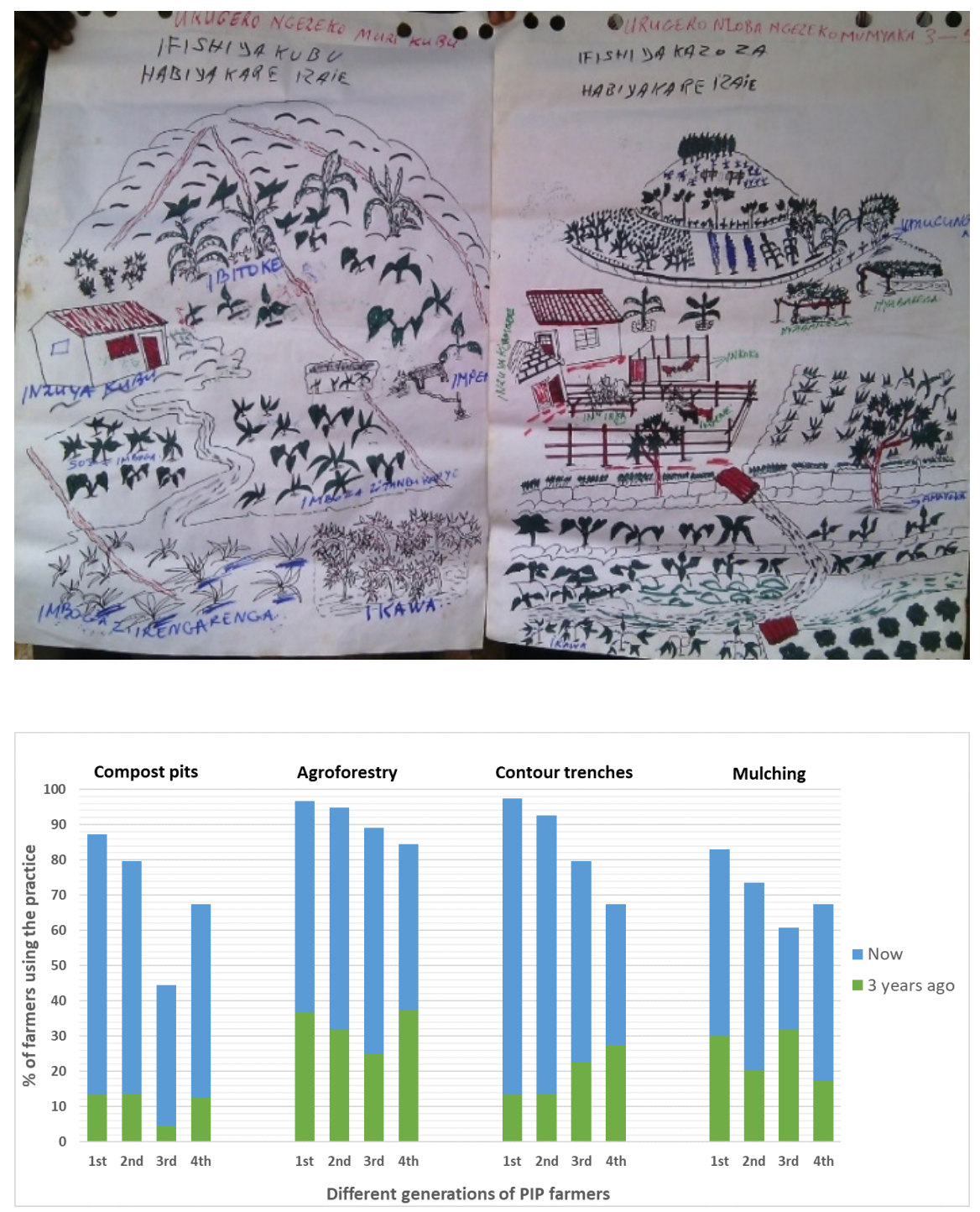

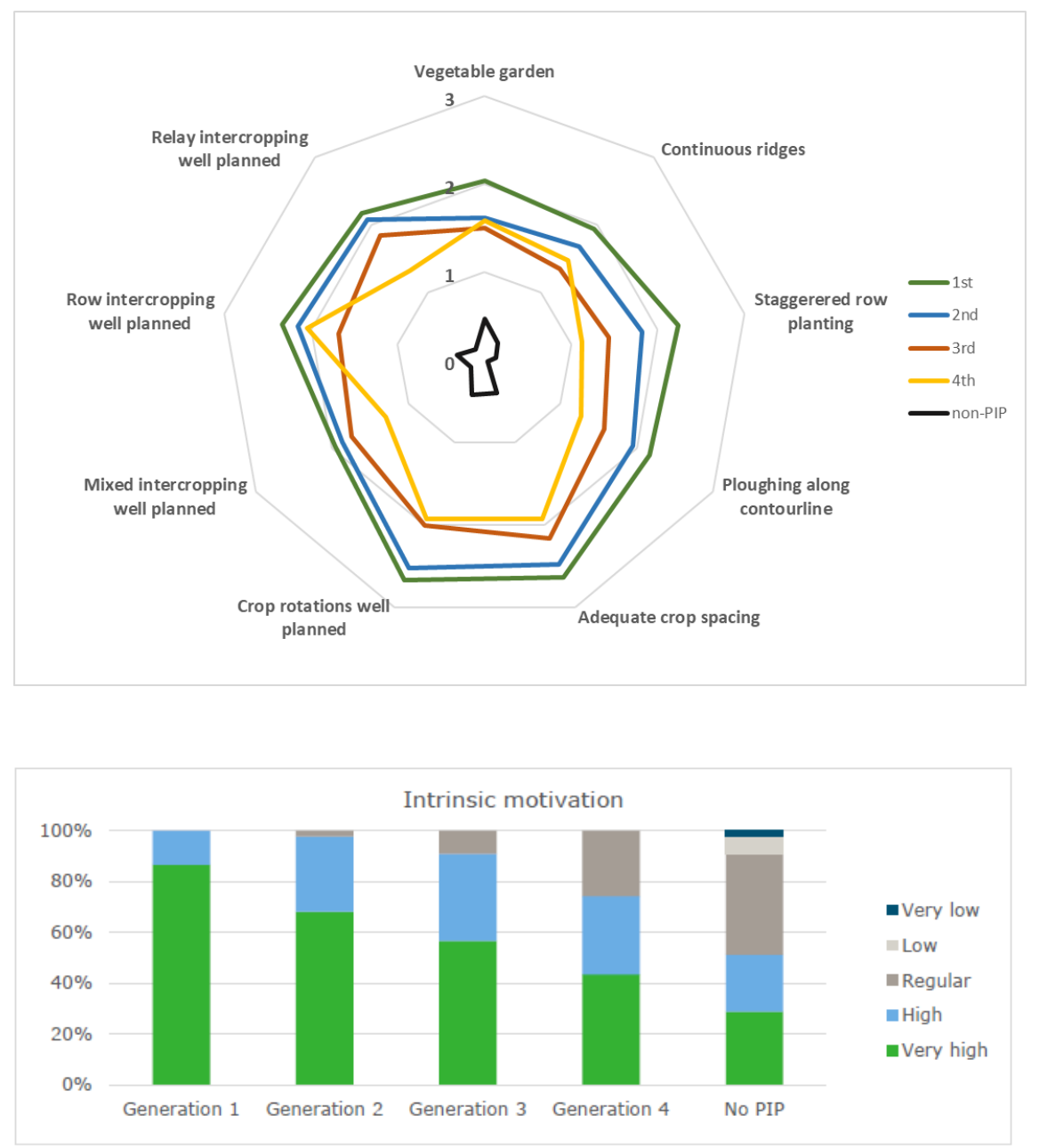